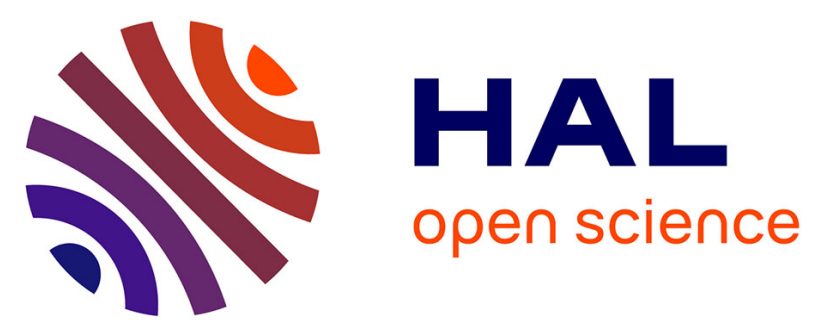

\title{
Dramatic response of STRN-NTRK -fused malignant glioneuronal tumor to larotrectinib in adult
}

Julie Boyer, Cristina Birzu, Franck Bielle, Clara Goulas, Julien Savatovsky, Carine Karachi, Ahmed Idbaih

\section{- To cite this version:}

Julie Boyer, Cristina Birzu, Franck Bielle, Clara Goulas, Julien Savatovsky, et al.. Dramatic response of STRN-NTRK -fused malignant glioneuronal tumor to larotrectinib in adult. Neuro-Oncology, 2021, 10.1093/neuonc/noab080 . hal-03251623

\section{HAL Id: hal-03251623 \\ https://hal.sorbonne-universite.fr/hal-03251623}

Submitted on 7 Jun 2021

HAL is a multi-disciplinary open access archive for the deposit and dissemination of scientific research documents, whether they are published or not. The documents may come from teaching and research institutions in France or abroad, or from public or private research centers.
L'archive ouverte pluridisciplinaire HAL, est destinée au dépôt et à la diffusion de documents scientifiques de niveau recherche, publiés ou non, émanant des établissements d'enseignement et de recherche français ou étrangers, des laboratoires publics ou privés. 


\section{Dramatic response of STRN-NTRK fused malignant glioneuronal tumor to}

Larotrectinib in adult

Key words: glioneuronal tumor, NTRK fusion, molecular targeted therapy.

Julie Boyer, Cristina Birzu, Franck Bielle, Clara Goulas, Julien Savatovsky, Carine Karachi, and Ahmed Idbaih.

Sorbonne Université, Inserm, CNRS, UMR S 1127, Institut du Cerveau et de la Moelle épinière, ICM, AP-HP, Hôpitaux Universitaires La Pitié Salpêtrière - Charles Foix, Service de Neurologie 2-Mazarin, F-75013, Paris, France (J.B., C.B., A.I.) ; Sorbonne Université, Inserm, CNRS, UMR S 1127, Institut du Cerveau et de la Moelle épinière, ICM, AP-HP, Hôpitaux Universitaires La Pitié Salpêtrière - Charles Foix, Service de Neuropathologie-Escourolle, F-75013, Paris, France (F.B.) ; AP-HP, Hôpitaux Universitaires La Pitié Salpêtrière - Charles Foix, Service de Pharmacie, F75013, Paris, France (C.G.); Service d'Imagerie Médicale, Hôpital Fondation Rothschild, F-75019, Paris, France (J.S.) ; Sorbonne Université, Inserm, CNRS, UMR S 1127, Institut du Cerveau et de la Moelle épinière, ICM, AP-HP, Hôpitaux Universitaires La Pitié Salpêtrière - Charles Foix, Service de Neurochirurgie, F75013, Paris, France (C.K.).

Corresponding author: Ahmed Idbaih, AP-HP, Hôpitaux Universitaires La Pitié Salpêtrière - Charles Foix, Service de Neurologie 2-Mazarin, 47-83 boulevard de l'Hôpital F-75013, Paris, France (ahmed.idbaih@aphp.fr, Tel 0033142160385, Fax $0033142160418)$. 
Glioneuronal tumors (GNT) are rare entities characterized by the proliferation of cells expressing a mixture of neuronal and glial markers. Most GNT are classified as lowgrade, but some may present high grade features.

We report here a case on a left-handed 53 year-old Caucasian man with no medical history who presented in 2011 with partial seizures, revealing a right non-enhancing insular brain lesion compatible with a diffuse low-grade glioma (Fig 1A). The lesion was therefore monitored and remained stable for 8 years. In June 2019 the patient presented rapid clinical and radiological tumor progression. The tumor was surgically removed. Pathological examination identified a high-grade GNT exhibiting frequent mitosis, vascular proliferation, necrosis, and Ki67 proliferative activity of $20 \%$. Immunohistochemistry analysis revealed no IDH1R132H, FGFR3, BRAFV600E mutations or EGFR expression. No microsatellite instability or $1 p 19 q$ codeletion was detected. In contrast, pan-TRK staining was positive (Fig 1B) and transcriptomic analysis revealed STRN1-NTRK2 fusion.

First line treatment included concurrent radiochemotherapy delivering 59.4 Gy plus Temozolomide, followed by 5 cycles of adjuvant Temozolomide, which ended in February 2020. Follow-up MRI showed tumor progression in March 2020 and led to the initiation of a second line treatment with Larotrectinib (TRK inhibitor) starting March $30^{\text {th }}, 2020$ with $75 \mathrm{mg}$ twice a day, to $100 \mathrm{mg}$ twice a day starting the $24^{\text {th }}$ of April, 2020.

The patient then remained clinically stable with minor troubles with word finding. The patient has presented no seizures since September 2019 and is currently being treated with regular anticonvulsant monotherapy. 
Follow-up MRI performed in June 2020 showed complete response, that was maintained in February 2021 (Fig 1C). Larotrectinib tolerance is good with no adverse events.

NTRK genes are involved in neurodevelopment, three NTRK genes are described: NTRK1, NTRK2 and NTRK3, which respectively encode transmembrane Tyrosine kinase Receptors TrkA, TrkB and TrkC proteins. When activated by their specific ligands (mainly neurotrophins and neuronal growth factors) Trk receptors lead to activation of intracellular downstream differentiation and proliferation signaling pathways.

NTRK fusions have first been described in 1982. Since the approval by the FDA of TRK inhibitors in 2018, NTRK fusions have been increasingly screened for in solid cancers, including in CNS tumors ${ }^{1}$. NTRK fusions' resulting chimera proteins show constitutive activation of the tyrosine kinase domain inducing aberrant cell proliferation (Fig 1D).

In 2017 Alvarez-Breckenridge et al. reported an STRN3-NTRK2 fused ganglioglioma (with no therapeutic implication) and a BCAN-NTRK1 fused low-grade GNT, which treated with Entrectinib, led to partial tumor response ${ }^{2}$.

A limited number of cases showing efficacy of Larotrectinib in pediatric NTRK fusionpositive intracranial tumors have been reported since $2018^{3}$. Although preclinical studies highlight a better CNS penetration for Entrectinib ${ }^{4}$, Larotrectinib has also been found in significant levels in brain homogenates ${ }^{5}$. The CNS penetration, paired with durable disease control in patients with both metastatic and primary CNS NTRK fused tumors (A. E. Drilon, unpublished data), in addition to a satisfying security profile, support Larotrectinib as a therapeutic option in these tumors. 
One case of ARHGEF2-NTRK1 fused high-grade GNT was described by Kurozumi et al. in $2019^{6}$, emphasizing the need for fusion testing in such tumors.

To our knowledge, our patient is the first one in the literature exhibiting a GNT with a gene fusion involving NTRK2 as oncogene and STRN1 as upstream gene partner. The pathological diagnosis of an unusual aggressive GNT lacking BRAFV600E mutation led to further molecular analysis and allowed identification of a specific druggable molecular alteration with clinical benefit for the patient.

This case illustrates the importance of complementary molecular analysis and the brain penetrance and efficacy of NTRK inhibitors in NTRK-fused high-grade GNT. 


\section{References}

1. Gambella A, Senetta R, Collemi G, et al. NTRK Fusions in Central Nervous System Tumors: A Rare, but Worthy Target. Int J Mol Sci. 2020;21(3). doi:10.3390/ijms21030753

2. Alvarez-Breckenridge C, Miller JJ, Nayyar N, et al. Clinical and radiographic response following targeting of BCAN-NTRK1 fusion in glioneuronal tumor. NPJ Precis Oncol. 2017;1. doi:10.1038/s41698-017-0009-y

3. Alharbi M, Mobark NA, Balbaid AAO, et al. Regression of ETV6-NTRK3 Infantile Glioblastoma After First-Line Treatment With Larotrectinib. JCO Precis Oncol. 2020;(4):796-800. doi:10.1200/PO.20.00017

4. Fischer $\mathrm{H}$, Ullah $\mathrm{M}$, de la Cruz CC, et al. Entrectinib, a TRK/ROS1 inhibitor with anti-CNS tumor activity: differentiation from other inhibitors in its class due to weak interaction with P-glycoprotein. Neuro-Oncol. 2020;22(6):819-829. doi:10.1093/neuonc/noaa052

5. Sparidans RW, Wang Y, Schinkel AH, Schellens JHM, Beijnen JH. Quantitative bioanalytical assay for the tropomyosin receptor kinase inhibitor larotrectinib in mouse plasma and tissue homogenates using liquid chromatographytandem mass spectrometry. J Chromatogr B. 2018;1102-1103:167-172. doi:10.1016/j.jchromb.2018.10.023

6. Kurozumi K, Nakano Y, Ishida J, et al. High-grade glioneuronal tumor with an ARHGEF2-NTRK1 fusion gene. Brain Tumor Pathol. 2019;36(3):121-128. doi:10.1007/s10014-019-00345-y

\section{Legend to Figure 1:}


A, brain MRI in 2012. From left to right: axial and coronal FLAIR, axial T1 gadoliniumenhanced section showing a right non-enhancing insular intraaxial lesion. B, from left to right: 1) epithelioid and ganglion-like tumor cells and microvascular proliferation ; 2) strong expression of the glial marker ; 3) heterogeneous expression of the neuronal marker ; 4) p53 strong and heterogenous staining ; 5) pan-TRK strong expression in tumor cells; 6 ) high proliferation index of $20 \%$. Images 2 to 6 were obtained using IHC (HE: hematoxylin-eosin, IHC: immunohistochemistry). C, T1 gadolinium-enhanced MRI measured tumor volume as a function of time and corresponding MRI scans. (RCT: radiochemotherapy). D, schematic representation of NTRK2-STRN1 fusion (TKD: Tyrosine Kinase Domain, CCD: Coiled Coil Domain).

\section{Acknowledgments}

The research leading to these results has received funding from the program "Investissements d'avenir" ANR-10-IAIHU-06. Institut Universitaire de Cancérologie INCA-DGOS-Inserm_12560 SiRIC CURAMUS is financially supported by the French National Cancer Institute, the French Ministry of Solidarity and Health and Inserm. Charlotte Bellamy for reviewing English. 
